\title{
EN EL CORAZÓN DE LA LIBERTAD: EL UNIVERSALISMO KANTIANO DESDE UNA APROXIMACIÓN DE GÉNERO
}

\author{
Stella VILLARMEA \\ Universidad de Alcalá
}

RESUMEN: La ética universalista sostiene que no hay distinciones morales que quepa atribuir a la diferencia genérica. La concepción de la ley moral que defiende Kant va unida al respeto y protección de las necesidades individuales (no del agente, sino de quienes le rodean). La apelación al imperativo categórico revela numerosos defectos morales en el trato que reciben las mujeres en virtud de su género.

ABSTRACT: For universalist ethics there are no moral distinctions based on gender differences. The Kantian notion of the moral law is linked to the respect and protection of the individual needs (of other people). The appeal to the categorical imperative helps revealing various moral faults in the moral treatment that women receive due to their gender.

\section{Introducción}

Este ensayo pretende extraer algunas implicaciones interesantes que la ética kantiana ofrece para el desarrollo de un feminismo moral. Defenderemos que el universalismo formal kantiano contiene elementos de indudable utilidad para el proyecto feminista. Esta defensa no nos impedirirá reconocer y rechazar los aspectos misóginos de la postura de Kant, aspectos que es imprescindible sacar a la luz para que formen parte del conocimiento general de este autor. Pero, más allá de este hecho, también pensamos que el núcleo esencial de la ética kantiana es no sólo perfectamente asimilable por un proyecto moral feminista sino justamente una muy buena manera de enfocarlo.

La defensa de la ética kantiana desde una perspectiva feminista puede resultar chocante a quienes se hayan familiarizado con las discusiones actuales en ética feminista, y especialmente a quienes hayan tenido algún contacto con la perspectiva que ha venido en denominarse "ética del cuidado", de tanta proyección en los últimos años. Desde esta y otras perspectivas similares, muchas pensadoras feministas han sido críticas con aquellos aspectos kantianos que supues- 
tamente primaban la generalidad y la abstracción sobre la particularidad y la atención a las necesidades concretas individuales. Así, el énfasis kantiano en la universalidad, su primacía de la autonomía frente a la vinculación y su visión de las mujeres como una clase inferior de personas le han hecho objeto de un duro rechazo por una parte influyente del feminismo actual.

Sin embargo, la lectura que hace la ética del cuidado de Kant es, a nuestro entender, enormemente simplificadora, y a veces incluso errónea. Al fin y al cabo, la fórmula kantiana de la moralidad exige que el agente actúe de tal manera que muestre respeto por los otros y por sí mismo. Y su apelación al reino de fines deja claro que hemos de pensar en la ley moral como una ley que guía los comportamientos de una comunidad de seres racionales dotados de deseos particulares, en vez de concebirla como una ley dirigida a individuos considerados de manera abstracta y aislada. En particular, la premisa del universalismo formal y la noción de lo que cabría denominar "deberes de amor práctico" constituyen una base sólida sobre la que poder construir un feminismo ético.

Merece la pena resaltar que la alternativa terminológica que acabamos de utilizar, siguiendo a Cèlia Amorós, no es una cuestión secundaria, esto es, que hay razones para preferir la noción "feminismo ético" a la de "ética feminista" ${ }^{1}$. El término "ética feminista" parece implicar que hay un tipo de ética que es feminista y otro, también legítimo en tanto que merecería la calificación de ética, que no lo es. Sería, por tanto, posible imaginar una ética no feminista. En cambio, la noción de "feminismo ético" parte de la idea de que cualquier teoría moral ha de cumplir ciertos requisitos, que tienen que ver con el trato que desde esa perspectiva ética obtendrían las mujeres. Por decirlo de modo breve, si es ética, ha de ser también feminista. En todo caso, y dada la complejidad de los asuntos humanos, el proyecto del feminismo ético cobra todo su sentido porque asume como prioridad teórica la necesidad de analizar las implicaciones que una determinada teoría moral tiene para las mujeres, y porque se compromete además a contribuir a diseñar la puesta en práctica de medidas laborales, políticas, sociales, jurídicas, etc., que acaben con la todavía demasiado frecuente discriminación (sería redundante añadir aquí, «moral») de las mujeres.

\footnotetext{
${ }^{1}$ Amorós, Cella (ed.), Feminismo y filosofia, Madrid, Síntesis, 2000, pp.9-10.
} 
Además, en el caso concreto que nos ocupa - la construcción de un feminismo moral à la kantiana - favorecemos la expresión «feminismo ético" en vez de "ética feminista" para enfatizar que no es necesario partir de la hipótesis de una supuesta diferencia en los razonamientos y comportamientos morales que emprende cada género, tal y como pretende la ética feminista del cuidado. Por el contrario, no hay por qué suponer que existen modos específicamente femeninos de pensar y actuar moralmente, ni que existan tampoco sus correspondientes versiones masculinas, pues el punto de partida de nuestra propuesta es la irrelevancia que tiene considerar el género del agente a la hora de decidir o juzgar la calidad de un hecho moral. Resulta interesante reparar en que esto no equivale a decir que el análisis haya de ser ciego o indiferente a los géneros de los sujetos implicados, ya que es precisamente cuando se tienen en cuenta éstos que salen a la luz ciertas asimetrías en el trato moral que unos y otras reciben.

\section{El chapapote kantiano}

Kant estaba convencido de que las mujeres eran incapaces de comportarse conforme a lo que él valoraba como el tipo ideal de moralidad. Esto equivale a considerar a las mujeres como una clase inferior de personas. Sobre la misoginia de Kant, tanto en lo referente a las cuestiones morales como en otros asuntos centrales relacionados con lo bello y lo sublime, la antropología o la política, hay publicada abundante bibliografia ${ }^{2}$. En este ensayo no hay espacio para una minima presentación interesante de sus tesis y argumentaciones a este respecto, ni tampoco para un análisis de los laberintos teóricos que la sustentan o de las implicaciones prácticas en que se traducen. Para nuestro propósito, basta recoger, a modo de ejemplo, unas cuantas citas: ${ }^{3}$

2 Schott, Robin (ed.) Feminist Interpretations of Immanuel Kant, University Park PA, Penn State Press, 1997. Grimshaw, Jean, Philosophy and Feminist Thinking, Minneapolis MN, University of Minnesota Press, 1986. Pía Jauch, Ursula, Immanuel Kant zur Geschlechterdifferenz, Vienna, Passagen, 1993. O'Neill, Onora, Constructions of Reason: Explorations of Kant's Practical Philosophy, Cambridge, Cambridge University Press, 1989. Denis, Lara, "From Friendship to Marriage: Revising Kant", Philosophy and Phenomenological Research, 43, 1, 2001.

${ }^{3}$ Lamentamos la vergüenza ajena que los siguientes comentarios puedan provocar, pero ya se sabe que en filosofía, como en otras áreas humanas, las figuras ideales, incluso las entronizadas por la academia, suelen terminar quebrando. Claro que, hay casos donde la "muerte del padre" resulta más fácil de llevar a cabo, habida cuenta de su necedad. 
- "Una mujer letrada, que tenga la cabeza llena de griego, como la Señora Dacier, o que sostenga discusiones profundas sobre mecánica, como la Marquesa de Châtelet, tendría además que tener barba; porque ésta expresaría mejor la imagen del pensamiento sesudo por el que luchan" (Observaciones sobre el sentimiento de lo bello y lo sublime, AK, II, 209).

- "Jamás una clase fría y especulativa, siempre sentimientos y de hecho los que sean lo más afines posibles a sus condiciones en cuanto sexo" (Observaciones sobre ..., AK, II, 231).

- «En lo que respecta a las mujeres cultivadas, éstas necesitan de sus libros acaso tanto como de su reloj; a saber, lo llevan para que se vea que tienen uno, tanto si está parado como si no está puesto en hora con relación al sol" (Antropología en sentido pragmático, $\mathrm{AK}, \mathrm{VII}, 307)$.

- «La mujer es un animal doméstico. El hombre camina por delante con las armas en la mano, y la mujer le sigue con la carga de los enseres de la casa” (Antropologia ..., AK, VII, 304).

- "Las mujeres evitan la maldad, pero "no porque sea injusta, sino porque es fea; $y$ las acciones virtuosas significan para las mujeres aquellas que son bellas ... El género femenino es insensible a todo lo que sea deber u obligación. Ellas hacen algo sólo porque quieren, y el arte consiste en hacer que quieran sólo lo que es bueno" (Observaciones sobre ..., AK, II, 231).

No son estos los únicos comentarios sexistas de nuestro autor a propósito de la naturaleza esencial de las mujeres, su capacidad para actuar moralmente, el tipo de educación que les corresponde o el papel social que debe esperarse de ellas. Y, desde luego, nada más lejos de mi intención que descargarle de responsabilidad apelando a algo así como la sociedad de su época. Afortunadamente, a estas alturas de la investigación histórica contamos con numerosos estudios que prueban cómo también en aquel tiempo existían vindicaciones activas que exigían la abolición del sexismo ${ }^{4}$; vindicaciones que constituyen precisamente el referente polé-

${ }^{4}$ WollstonecrafT, Mary, Vindicación de los derechos de la mujer, Madrid, Cátedra, 1996. De la Barre, Poulain, "Sobre la igualdad de los sexos", en A. Puleo (ed.) Figuras del Otro en la Ilustración francesa, Madrid, Escuela Libre Editorial, 1996. Condorcet, DE GOUGES, DE LAMBERT y otros, La Ilustración olvidada: La polémica de los sexos en el siglo XVIII, ed. de A. Puleo, Madrid, Anthropos-Comunidad de Madrid, 1993. SCHNEIR, MIRIAM, Feminism: The Essential Historical Writings, New York, Vintage Books, 1972. 
mico con el que contrasta la toma de postura de Kant. Queda entonces apuntado en general el carácter misógino de Kant y, más en particular, dado que ello es lo que nos interesa en este ensayo, el elemento sexista sobre el que pivota su concepción de la moralidad de las mujeres 5 .

\section{Voluntariado en acción}

Dicho todo lo anterior, todavía queda tarea por delante, pues lo interesante es ver si las categorías básicas de la ética kantiana contienen elementos que pueden ser apropiados por el feminismo, con independencia de qué fuera lo que el propio Kant pensaba sobre las diferencias de género. Es cierto que el contenido de las citas mencionadas no juega un papel simplemente anecdótico en el pensamiento de Kant sino que forma parte de un sistema ensamblado. Lo cual quiere decir que buena parte del sistema queda afectado si eliminamos estos aspectos por considerarlos reprobables. En este sentido, numerosos estudios muestran cómo la cara vista de la ética kantiana (emancipación, libertad, ciudadanía, derechos y demás bagaje ilustrado) se apoya en una cara oculta mucho más siniestra que limita el acceso a las realidades que esos conceptos refieren, de entre otros, las mujeres. No obstante, todavía creemos posible visitar de nuevo a Kant y concentrarnos en algunos aspectos esenciales de su planteamiento moral, de forma que podamos extraer de él algunas virtualidades emancipadoras de interés para el proyecto feminista. Ése será, pues, nuestro método de trabajo.

La filosofía moral de Kant pretende ser una investigación peculiar de la vida moral. El filósofo de Könisberg supuso que hay una vida moral en sentido ordinario, una conciencia moral común a todas las personas y a todos los tiempos, que es independiente de su indagación filosófica. Los análisis filosóficos de la vida moral ni quitan ni añaden nada a ésta. Lo único que hacen es clarificarla, es decir, indicar en qué consiste, en dónde reside exactamente y cómo es posible eso que llamamos

${ }^{5}$ Mostrar con claridad este elemento exigiría extraer todas las implicaciones que contiene la última de las citas aludidas, esto es, la asociación de la mujer con el sentimiento de lo bello pero no con la noción de deber moral. Ello requeriría un tiempo y espacio que no puedo emplear aquí, pero puede consultarse: J. Perona, Ángeles, «Sobre incoherencias ilustradas: una figura sintomática en la universalidad" y Posada Kubissa, Luisa, "Kant: de la dualidad teórica a la desigualdad práctica", ambos en C. Amorós (coord.) Actas del Seminario Permanente Feminismo e Ilustración 19881992, Madrid, Instituto de Investigaciones Feministas de la Universidad Complutense-Dirección General de la Mujer de la Comunidad Autónoma de Madrid, 1992. Schott, Robin, Cognition and Eros: A Critique of the Kantian Paradigm. University Park PA, Penn State Press, 1990. 
moralidad, para que sepamos en todo momento, una vez terminada la investigación y sistematizada adecuadamente, cuál es la guía segura de la moralidad.

El objeto de la filosofía es analizar esta vida y esta conciencia morales con el fin de averiguar cuál ha de ser el carácter de nuestros conceptos y preceptos morales para que la moralidad sea posible. Kant habla de las condiciones de posibilidad de la vida moral en un sentido universal. Es posible que en diferentes sociedades y culturas haya diferentes normas de conducta moral, pero si son normas morales, entonces será posible hallar qué es lo que tienen en común, qué es lo que las hace ser morales. Su análisis de la moralidad remite así a un ideal de validez general.

De ahí que la Fundamentación de la metafisica de las costumbres comience preguntándose lo que significa universalmente "bueno", esto es, qué ideal tenemos en mente todos (tanto las mujeres como los varones) cuando usamos el término «bueno" en sentido moral. Pues bien, su famosa propuesta es que: «Ni en el mundo ni, en general, fuera de él es posible pensar nada que pueda ser considerado bueno sin restricción excepto una buena voluntad) (Kant, Fundamentación, 53) ${ }^{6}$. Se hace entonces preciso aclarar qué sea eso de una voluntad buena. La respuesta, en terminología kantiana, es: una voluntad que actúa por un motivo de respeto a la ley moral o deber (por qué lo quiero hacer) y por una intención que es conforme a la ley moral (qué quiero hacer).

Como hemos visto en la sección anterior, Kant pone límites a la capacidad de las mujeres para poseer una buena voluntad en términos absolutos, puesto que de ellas cabe esperar que actúen (¿con más frecuencia? o, peor incluso, ¿`iempre?) movidas por sus inclinaciones en vez de por la noción estricta de deber. Pero la lectura de los escritos morales de Kant deja meridianamente claro además que el ideal de buena voluntad (la que actúa por deber conforme al deber) resulta difícil de cumplir también para los varones. Aunque ellos tengan, faltaría más, la capacidad que se requiere - esto es, la capacidad de juzgar y de actuar por principios generales al margen de sus propias inclinaciones-, no siempre la ejercen. Y aunque la ejerzan, dada la imposibilidad de autoconocimiento moral perfecto en la ética kantiana, nunca podrán saber si actúan por deber o por inclinación en aquellos casos en los que la acción es conforme a la ley moral. Lo cual implica que nunca puedan tener conocimiento de su calidad moral; incluso si se están haciendo bue-

${ }^{6}$ Las citas corresponden a la versión española: Kant, Immanuel, Fundamentación de la metafisica de las costumbres, ed. de L. Martínez de Velasco, Madrid, Espasa Calpe, 1990. 
nos en sentido moral no podrán tener certeza apodíctica de ello. Luego desplegar una buena voluntad y ser consciente de ello es, en realidad, complicado tanto para unos como para otras (si bien por razones distintas).

Pues bien, denunciar que la interpretación kantiana de quién está en mejor posición para cumplir con la ley moral por el motivo adecuado va ligada a una construcción patriarcal de los géneros, es consistente con defender que el concepto de moralidad kantiano, en tanto que apela a la universalidad, sigue siendo relevante para el feminismo. La razón por la que una ética universalista es, a nuestro entender, interesante para el feminismo radica en la premisa de que lo que manda lo manda para todos y todas por igual, esto es, en la tesis de que no hay distinciones morales que quepa atribuir a la diferencia genérica. Desde esta perspectiva, no nos interesan tanto las teorías particulares de Kant sobre los géneros como el impulso que sus categorías morales puedan ofrecer al feminismo ético.

Ahora bien, sería equivocado pensar que la estrategia de análisis consiste simplemente en obviar lo que en relación con las mujeres dijo un día Kant, y extenderles las consideraciones que consideraba exclusivamente pertinentes para los varones. Un proceso de depuración del sexismo de este estilo no precipita por sí solo conclusiones que puedan considerarse propiamente feministas. No; para que la ética kantiana rinda todas sus potencialidades liberadoras y emancipadoras aún es preciso que la filtremos un poco más y extraigamos su verdadero poso valioso. A perfilar ese método exprimidor está dedicada la siguiente sección.

\section{Universalismo kantiano y feminismo ético: historia de una atracción}

\subsection{Algunos aspectos centrales de la ética kantiana}

El núcleo del universalismo kantiano reside en presentar una única regla formal que sirva como criterio para juzgar si la intención de mi acción (lo que quiero hacer) es conforme con la ley moral (lo que debo hacer). Esta regla tiene el aspecto de un imperativo categórico y es susceptible de varias formulaciones. De acuerdo con la segunda de las formulaciones, el imperativo dice así: «Obra de tal modo que te relaciones con la humanidad, tanto en tu persona como en la de cualquier otro, siempre como un fin, y nunca sólo como un medio" (Fundamentación, 104). 
Comprender esta formulación requiere entender las nociones kantianas de medio y fin, y su relación con las nociones de cosa y persona. Todo lo que es un mero medio para un fin posterior es una simple "cosa", en un sentido amplio de este concepto. Un martillo es una cosa porque es un instrumento para clavar clavos u objetos semejantes. Es claro que una persona puede ser tratado como una cosa, como un puro medio, si la utilizamos solamente para determinados fines. Cuando se esclaviza o somete a tortura a alguien, lo estamos considerando no como una persona, sino como una cosa: es aquello que nos sirve para arar el campo y recoger algodón, como si fuera un apero de labranza más, o que nos sirve para obtener cierta información que queremos. Sin embargo, sostiene Kant, los seres racionales como nosotros, precisamente por ser racionales, no podemos ser meras cosas ni ser tratados como tales en ninguna circunstancia. Los seres racionales somos personas. $Y$ las personas son fines en sí mismos, es decir, seres que deben ser respetados, seres que no pueden ser tratados a capricho como puros medios, seres que tienen dignidad.

Como todas las cosas son medios, no pueden tener más que un valor relativo, nunca absoluto. Tienen valor en tanto que nos sirvan para algo, para aquello respecto de lo cual las usamos. El martillo nos sirve, nos es útil, tiene valor, mientras cumpla bien la función para la cual lo empleamos. Si se rompe, lo podemos tirar a la basura sin violar ninguna norma moral. Las cosas, por tanto, tienen sólo valor relativo, que es siempre un valor de uso, y viceversa. Las personas, por el contrario, no son cosas, precisamente porque su valor es absoluto, nunca un medio para un fin ulterior, nunca algo que pueda ser usado en relación con ningún interés, ni abandonado, tirado o asesinado si no cumple con la función que nos conviene.

Es gracias al valor absoluto de las personas, a su racionalidad, por lo que la noción de persona, de humanidad, puede formar parte de aquello sobre lo cual puede fundarse un valor absoluto, incondicionado, es decir, un imperativo moral. Sobre el valor relativo de las cosas sólo se podría fundar la validez de un imperativo hipotético. En este último caso, sólo si queremos obtener un fin deseado, debemos servirnos de la cosa como medio adecuado para ese fin. Ahora bien, una persona, por su valor incondicionado y absoluto, nunca puede formar únicamente parte de lo que deberíamos utilizar cuando queremos un fin determinado. Esta idea es la que se recoge en la segunda formación del imperativo categórico mencionada. 
Por otra parte, la tercera formulación del imperativo categórico quiere expresar la idea de que debemos actuar de tal forma que nuestra voluntad, por ser la voluntad de un ser racional, pueda convertirse en una voluntad universalmente legisladora. Para Kant, cuando la voluntad puede hacer esto, es que es una voluntad autolegisladora, autónoma, una voluntad que se somete solamente a una ley de la que ella misma es autora, que promulga y quiere de una forma desinteresada. Precisamente porque quiere esa ley de una forma que no tiene en cuenta intereses particulares, ni siquiera los intereses del sujeto que tiene esa voluntad, es por lo que puede ser universalmente legisladora y puede convertirse en el fundamento de un imperativo categórico.

Lo importante en este caso es que pensemos, aunque nos resulte sumamente extraño, en la posibilidad de que alguien acepte una legislación que se da a sí mismo y que esa legislación sea al mismo tiempo universal. Y será universal no porque el individuo la imponga con éxito a la fuerza a todos los demás, sino porque, dado que no ha surgido de ningún interés individual en función de fines particulares en tanto que son los fines de alguien que ocupa determinada situación social, profesional, política o económica, sino de su voluntad como ser racional, de lo que su voluntad descarnada se ha propuesto a sí misma, es lo que cualquier voluntad de un ser racional querrá. Por decirlo así, todos estarían voluntariamente dispuestos a regirse por la ley que esa voluntad particular se ha dado a sí misma. Como dice Kant, lo que esa voluntad quiera formará parte de un reino universal de fines que todo ser racional, por serlo, también estaría dispuesto a querer.

Luego de acuerdo con la tercera de estas formulaciones, este imperativo exige que respetemos la autonomía de voluntad de cada ser humano (tanto la mía como la de cualquier otra persona). El principio de la autonomía de la voluntad significa considerar "la voluntad de todo ser racional como una voluntad universalmente legisladora ... De esta manera la voluntad no está sometida sin más a la ley, sino que lo está de manera que puede ser considerada autolegisladora, y por eso mismo, y sólo por eso, sometida a aquella ley de la que ella misma es autora" (Fundamentación, 107).

Pues bien, al explicar estas formulaciones, Kant destacá dos aspectos. En primer lugar, tal y como desarrolla la segunda formulación, el imperativo categórico implica una prohibición según la cual las personas no deben ser nunca instrumentalizadas: todo ser racional «debe tratarse a sí mismo y tratar a todos los 
demás nunca como simple medio sino siempre al mismo tiempo como fin en sí mismo" (Fundamentación, 110). En segundo lugar, el precepto de que la humanidad debe ser valorada siempre "como un fin en sí mismo" está ligado al reconocimiento de que ser una persona - al contrario de lo que supone ser una cosa- implica ser capaz de determinar desde sí misma los propios fines: «La razón vincula pues toda máxima de la voluntad como universalmente legisladora a cualquier voluntad y también a cualquier acción para consigo misma, y esto no en virtud de ningún otro motivo práctico o en vista de ningún provecho futuro, sino por la idea de la dignidad de un ser racional que no obedece otra ley que aquella que él se da a sí mismo" (Fundamentación, 112). En esto precisamente consiste la autonomía humana.

Es importante entender que estos dos aspectos suponen un desarrollo progresivo del concepto de moralidad, de manera que el segundo matiza y amplía los deberes exigidos por el primero. En efecto, desde el punto de vista de la caracterización negativa que contiene la prohibición, cualquier acción que aspire a ser moralmente correcta debe evitar usar a las personas "como un simple medio". Pero desde la perspectiva de la caracterización positiva que reconoce la capacidad de autodeterminación de cada ser humano, actuar moralmente bien no equivale simplemente a abstenerse de hacer daño. En realidad, la acción moral debe garantizar algo más. ¿¿En qué consiste exactamente esta condición añadida, esa otra contribución que debe introducir el agente moral?

La contestación a este interrogante pasa por recordar que Kant distingue el imperativo categórico de la denominada regla de oro, es decir, del conocido principio: "haz como quieras que te hagan». La insuficiencia de este último principio estriba en que nos libera de la obligación de hacer el bien, a cambio de evitar pedir a los demás que nos lo hagan a nosotros. La cita, aunque larga, merece la pena recoger aquí: "Una cuarta persona a quien le van bien las cosas ve a otros luchando contra grandes dificultades. Podría ayudarles, pero piensa: ¡a mí qué me importa? ¡que cada uno sea lo feliz que el cielo le conceda o él mismo quiera hacerse; nada voy a quitarle, y ni siquiera le tendré envidia; no tengo ganas de contribuir a su bienestar o a su ayuda en la necesidad! Ciertamente, si tal modo de pensar fuese una ley universal de la naturaleza podría muy bien subsistir la raza humana, y sin duda, mejor aún que charlando todos de compasión y benevolencia, poniéndolas por las nubes e incluso ejerciéndolas en ocasiones, pero también engañando en cuanto se tiene la oportunidad, traficando con el derecho de los hombres o lesionándolo de varias maneras. Pero bien, sea como fuere, aun cuando sea posible que 
aquella máxima se mantenga como ley natural universal, es imposible, sin embargo, querer que tal principio valga siempre y por todas partes como ley universal, es imposible, sin embargo, querer que tal principio valga siempre y por todas partes como ley natural, pues una voluntad que así lo decidiera se contradiría a sí misma, ya que podría suceder algunos casos en que necesitara del amor y compasión de los demás, y entonces, por la misma ley natural originada en su propia voluntad, se vería privado de toda esperanza de ayuda.» (Fundamentación, 95) ${ }^{7}$.

Hay en esta cita dos aspectos que, bien entendidos, nos ayudarán a valorar la profundidad de la ética kantiana. Son, por una parte, los conceptos de amor y compasión hacia los demás y, por otra, los de necesidad, bienestar y felicidad. Analicémoslos por separado.

En primer lugar, la apelación al amor y compasión que debemos a los demás parece introducir una tensión insalvable en la argumentación kantiana. «Cómo! - diría alguien- ¿significa esto que debemos actuar movidos por un sentimiento de inclinación hacia los demás? Pero, ¿no había repetido Kant hasta la saciedad que el único motivo de actuación moralmente válido era el deber, y no la inclinación, el gusto, la compasión, la simpatía, un sentimiento de afecto, etc.?» Dicho de otro modo, si Kant distingue entre actuar movidos por la inclinación y actuar por estricto respecto al deber, ¿a qué viene hablar ahora de deberes de amor?

El foco de confusión se disuelve al tener en cuenta que Kant señala dos sentidos de amor, compasión, cuidado o benevolencia: de un lado, el emocional, subjetivo y regido por las inclinaciones $y$, de otro, el racional, objetivo y regido por la razón; expresado en sus propios términos, el amor patológico y el práctico. La distancia entre ambos sentidos se muestra en la siguiente cita: "Así hay que entender, sin duda alguna, los pasajes de la Escritura en donde se ordena que amemos al prójimo, incluso al enemigo. En efecto, el amor como inclinación no puede ser mandado, pero hacer el bien por deber, aun cuando ninguna inclinación le empuje a ello y hasta oponga una aversión natural e invencible, es amor práctico y no patológico [en el sentido de pathos, no de enfermedad], amor que tiene su asiento en la voluntad y no en una tendencia de la sensación, amor que se fundamen-

${ }^{7}$ Puede sorprender la introducción de este ejemplo en una moralidad a priori. Sobre este punto puede consultarse la nota que introduce Luis Martínez de Velasco en su traducción espanola del texto (Fundamentación, 95, nota 13). 
ta en principios de la acción y no en la tierna compasión, y que es el único que puede ser ordenado" (Fundamentación, 62). En otro lugar, Kant dice también que "la benevolencia (Wohlwollen) por principios, no por instinto, tiene un valor interior" (Fundamentación, 112). Queda explicado, pues, de qué manera la noción de deberes de amor desarrolla y explicita lo que ordena el imperativo categórico.

En segundo lugar, el reconocimiento por parte de Kant del papel que juega la necesidad, el bienestar y la felicidad en las vidas humanas explica también que la interpretación del imperativo categórico haya de ser más exigente que la regla de oro, entendida ésta en sentido estricto. De manera realista, Kant observa que la búsqueda de felicidad es un fin natural para todos los seres humanos, si bien cada persona la busca de una forma particular: "Hay un fin que puede presuponerse como real en todos los seres racionales ... hay un propósito que no sólo pueden tener, sino que puede ponerse con total seguridad que todos tienen por una necesidad natural, y éste es el propósito de felicidad» (Fundamentación, 84-85). «Pero es una desgracia que el concepto de felicidad sea un concepto tan indeterminado que, aun cuando todo ser humano desea alcanzarla, nunca puede decir de una manera bien definida y sin contradicción lo que propiamente quiere y desea. Luego, no sólo ocurre que la felicidad no puede ser definida de una forma universalmente válida, sino que tampoco sucede que cada individuo disponga de una definición concreta válida para sí mismo.»(Fundamentación, 88) ${ }^{8}$.

El argumento de Kant a este respecto parte de la observación de que, si bien los humanos son iguales en lo que se refiere a su capacidad de autodeterminación (todos tienen esta facultad), es precisamente por el uso de esta facultad que aparecen diferencias entre ellos. Todas las personas tenemos la capacidad de autodeterminación, pero cada cual la aplica de diferente manera, pues cada quien escoge de forma individual sus fines.

${ }^{8} \mathrm{La}$ cita continúa así: "Es imposible que un ser ... finito se haga un concepto determinado de lo que propiamente quiere. Si quiere riqueza ¡cuántas preocupaciones, cuánta envidia, cuántas acechanzas no podrá atraerse con ella! ¿Quiere conocimiento y saber? Pero quizá esto no haga sino darle una visión más aguda que le mostrará más terribles aún los males que ahora están ocultos para él y que no puede evitar, o impondrá a sus deseos, que ya bastante le dan que hacer, necesidades nuevas. ¿Quiere una larga vida? ¿Quién le asegura que no ha de ser una larga miseria? ¿Quiere al menos tener salud? Pero ¿no ha sucedido muchas veces que la flaqueza del cuerpo le ha evitado caer en excesos que habría cometido de haber tenido una salud perfecta?". 
Tomarse en serio la concepción particular de la felicidad que cada quien tenga, no es sino otra manera de entender el requerimiento que implica la ley moral de reconocer a cada persona su capacidad de autodeterminación. Lo cual significa que es un deber para el agente, en tanto sea posible y consistente con otros aspectos morales, apoyar a los demás en su búsqueda individual de su propio ideal de felicidad. La idea de que no basta con no impedir la felicidad a los demás sino que se debe colaborar activamente a su consecución y aumento, la señala Kant explícitamente en la siguiente cita: "Con respecto al deber meritorio para con los demás, el fin natural que tienen todos lo hombres es su propia felicidad. Es bien cierto que podría mantenerse la humanidad aunque nadie contribuyera a la felicidad de los demás, con tal de no sustraerles nada, pero es una concordancia meramente negativa y no positiva con la humanidad como fin en sí el que nadie se esfuerce en lo que pueda por fomentar los fines ajenos. En efecto, siendo el sujeto un fin en sí mismo, sus fines deben ser, en la medida de lo posible, también míos, si es que aquella representación ha de ejercer sobre mí todo su efecto" (Fundamentación, 106).

En resumen, la ética kantiana subraya no sólo que debemos abstenernos de hacer el mal y respetar los fines de los demás (la particular concepción de la felicidad de cada individuo), sino que debemos contribuir positivamente a que los demás sean felices. Luego la regla que nos sugiere Kant es a la vez estrictamente universal en su forma (se aplica a todo el mundo de igual manera) y radicalmente individual en el contenido de su aplicación (requiere que percibamos y apoyemos las necesidades específicas de los demás).

\subsection{Utilidad de la perspectiva kantiana para el feminismo ético}

Estamos ahora en condiciones de' extraer algunas implicaciones interesantes que la ética kantiana ofrece para el desarrollo de un feminismo moral ${ }^{9}$. En lo anterior se ha mostrado que la concepción universalista de la ley moral que defiende Kant va unida al respeto y protección de las necesidades individuales (de los demás). El feminismo ético puede adoptar con provecho esta tesis y desarrollarla de manera que tenga la misma relevancia en el caso de las mujeres que en el de

${ }^{9}$ El planteamiento general de esta sección está inspirado en el artículo de Herta Nagl-Docekal, "Feminist Ethics: How It Could Benefit from Kant's Moral Philosophy», en Schott, Robin (ed.) Feminist Interpretations of Immanuel Kant, University Park PA, Penn State Press, 1997, pp. 101-124. 
los hombres. El método de análisis que proponemos consiste en aplicar el universalismo formal para analizar las prácticas morales hacia las mujeres que permean todas las esferas de la vida actual. La apelación al imperativo categórico revela numerosos defectos morales del trato que reciben las mujeres en virtud de su género. Es así como el recurso a Kant abre para el proyecto feminista un campo de investigación enormemente interesante y fructífero, en el que poder no sólo criticar moralmente las prácticas discriminatorias sino justificar esa crítica utilizando precisamente el universalismo formal.

Un proyecto de este estilo adopta, como bien señala Dogl-Nacekal los siguientes tres aspectos, en tanto que esenciales a la ley moral kantiana: 1) la prohibición de utilizar a la gente simplemente como medios, 2) el deber de respetar los fines autodeterminados por los demás sujetos (fines que, por supuesto, están sujetos a ciertas limitaciones morales), y 3 ) el precepto de contribuir o ayudar a que las personas consigan dichos fines que se autodeterminan para sí mismas. Cada una de estas categorías arroja luz cuando se contempla desde la perspectiva de género, tal y como exponemos a continuación.

La ventaja del primer aspecto descansa en permitirnos juzgar como inmorales diferentes tipos de explotación a las mujeres, tales como la prostitución internacional, el acoso sexual, la violencia en el hogar, o la pornografía, por ejemplo. Otros modos de instrumentalización son la división por géneros del trabajo doméstico o del trabajo en general,.y la expectativa generalizada de que las mujeres dediquen buena parte de sus esfuerzos y energías a la gestión emocional de familia, allegados y amistades. Esta perspectiva arrojaría también luz sobre muchas formas de discriminación laboral. Las mujeres siguen estando asociadas a los trabajos peor remunerados o no remunerados en absoluto: ¿cabe mayor instrumentalización que ésa? ¿Y qué decir, por ejemplo, de la instrumentalización que supone en nuestro país el hecho de que la enorme valoración simbólica de la función procreadora de las mujeres no vaya acompañada de la puesta en marcha de medidas que faciliten o apoyen esta labor, sino con frecuencia por la culpabilización social derivada de no contribuir en suficiente medida a la deseada renovación generacional? Como se puede apreciar, la lista de asuntos a los que se puede aplicar este tipo de análisis es realmente extensa.

Por su parte, el segundo aspecto señala que la obligación de respetar las opciones individuales que corresponden a diferentes concepciones de felicidad, siempre y cuando cumplan con los parámetros morales, debe valer para las vidas 
de las mujeres tanto como para las de los varones. Lamentablemente, los datos que ofrecen los estudios sociales muestran que las mujeres no son percibidas como individuos por sus conciudadanos de la misma manera en que lo son los varones. En general, los roles sociales ligados al género presentan menos opciones, y ofrecen por tanto menos oportunidades de realización personal, en el caso de las mujeres que en el de los varones. Un ejemplo evidente, en la línea que acabamos de apuntar, es el hecho de que las mujeres se encuentren teniendo que elegir entre carrera o maternidad con mucha mayor frecuencia que los hombres, o que mantengan ambos proyectos con terribles tensiones y esfuerzos, para nada equivalentes a los que dedican los varones. En buena medida, sigue siendo en relación con la identidad sexual, el cuerpo, la maternidad y el trabajo donde perdemos o ganamos nuestro derecho a imaginar qué queremos ser.

Por último, la tercera categoría nos obliga a preguntar hasta qué punto encuentran las mujeres apoyo en su búsqueda individual de felicidad. Se arroja luz así sobre lo inaceptable de muchas situaciones en las que a las mujeres se les niega el apoyo necesario para perseguir los fines vitales que ellas mismas han elegido. En este sentido, baste recordar que la distancia que media entre la igualdad de derechos formal o jurídica y su plasmación en la práctica, resulta especialmente grande en el caso de las mujeres. Para que la igualdad de oportunidades deje de ser una cuestión de iure y pase a ser de facto, es necesario garantizar que las mujeres accedan (en la misma medida en que lo hacen los varones) a las oportunidades que legalmente les corresponden y de las que depende (idealmente) que vivan el tipo de vida que cada una escoja. Desde este punto de vista, medidas tales como la acción positiva o la regulación de la participación por cuotas adquieren su justificación moral desde el momento en que intentan, precisamente, acabar con esas situaciones.

En cualquier caso, y a fin de evitar cómodas objeciones de partida que califiquen el proyecto de utopía fantasiosa (en el sentido negativo de impracticable), debe quedar claro que el patrón de medida con el que valorar moralmente las distintas situaciones, es simplemente que las mujeres consigan lo mismo que disfrutan en términos generales los sujetos masculinos, ni más ni menos. A este respecto, la gran ventaja de analizar estos temas desde la perspectiva del imperativo categórico, es contemplar las asimetrías concretas de género como asuntos de carácter moral, en vez de como problemas que surgen de un conflicto de intereses entre grupos.

En suma, y como bien señala Nagl-Docekal en el artículo citado, el feminismo ético contemporáneo podría beneficiarse de la filosofía moral kantiana por 
dos razones. En primer lugar, porque esta filosofía ofrece un instrumento crítico para sacar a la luz por qué y de qué modo la subordinación de las mujeres es un mal moral. En segundo lugar, porque el pensamiento de Kant permite reflexionar sobre los cambios que se necesitan promover en la concepción más o menos típica de los géneros y en sus prácticas subsecuentes para permitir que las mujeres, tanto como los hombres, encuentren y gocen de la simpatía y el apoyo individual y social que necesitan para continuar recorriendo sus propios caminos hacia la felicidad.

Sin embargo, me gustaría acabar este trabajo mencionado una cautela. Es verdad que la confianza en la regulación por la sanción y el olvido consiguiente de otras formas de motivación de la acción moral han sido a veces fuente de debilidad para el feminismo contemporáneo. Desde esta perspectiva, el énfasis en la necesidad de empatizar con los derechos ajenos, al margen de la coacción, es comprensible. Incluir los fines de los demás entre mis propios fines es, desde luego, una definición preciosa de amor, que puede sugerir análisis y conclusiones tanto morales como políticos. Pero sigue siendo una cuestión abierta si es sobre esta definición de amor que debamos a montar la acción política. Que la ética nos mande amar puede considerarse (o no) una obligación excesiva. En todo caso, debemos evitar que una ética de máximos nos impida asegurar una política de mínimos. 